\title{
High Frequency of Juxtamembrane Domain ERBB2 Mutation in Gastric Cancer
}

\author{
SUJIN PARK ${ }^{1}$, SOOMIN AHN ${ }^{1}$, DEOK GEUN KIM ${ }^{2,3}$, HYUNJIN KIM ${ }^{1,4}$, \\ SO YOUNG KANG ${ }^{1}$ and KYOUNG-MEE KIM ${ }^{1,2,4}$ \\ ${ }^{1}$ Department of Pathology and Translational Genomics, Samsung Medical Center, \\ Sungkyunkwan University School of Medicine, Seoul, Republic of Korea; \\ ${ }^{2}$ Department of Clinical Genomic Center, Samsung Medical Center, Seoul, Republic of Korea; \\ ${ }^{3}$ Department of Digital Health, Samsung Advanced Institute of Health Science and Technology, \\ Sungkyunkwan University, Seoul, Republic of Korea; \\ ${ }^{4}$ Center of Companion Diagnostics, Samsung Medical Center, Seoul, Republic of Korea
}

\begin{abstract}
Background/Aim: ERBB2 mutation is an emerging therapeutic target in solid tumors; its therapeutic responses depend on the location of mutation. In gastric cancer, the profiles of ERBB2 mutations and their relationship with human epidermal growth factor receptor 2 (HER2) overexpression remain unknown. We aimed to describe the details of ERBB2 mutations in gastric cancer. Patients and Methods: Comprehensive panel sequencing was performed in 234 advanced gastric cancer patients. We investigated hotspots and clinicopathologic features of ERBB2 mutant gastric cancer in a single institute and evaluated the hotspots of ERBB2 mutation in a public database. Results: Eighteen patients (7.7\%) had ERBB2 mutations. The most frequent mutation was p.Arg678Gln (42.1\%), which was located in the juxtamembrane domain and was the most common mutation in public databases (20.5\%). All 18 ERBB2-mutant patients were negative for HER2 expression. Co-occurring genetic alterations included KRAS, PIK3CA, and ATM mutations. Conclusion: ERBB2 mutations were not associated with HER2 overexpression in gastric cancer patients. The most common mutation was located in the juxtamembrane domain of ERBB2.
\end{abstract}

This article is freely accessible online.

Correspondence to: Soomin Ahn, MD, Ph.D., Department of Pathology and Translational Genomics, Samsung Medical Center, Sungkyunkwan University School of Medicine, \#81, Irwon-ro, Gangnam-Gu, Seoul 06351, Republic of Korea. Tel: +82 234100833, Fax: +82 234106396. e-mail: suminy317@gmail.com

Key Words: HER2, ERBB2 mutation, gastric cancer, target therapy.
$E R B B 2$, widely known as human epidermal growth factor receptor 2 (HER2), is a proto-oncogene on chromosome $17 \mathrm{q} 21$ that encodes a transmembrane protein with tyrosine kinase activity and is involved in pathways that lead to cell growth and differentiation (1). ERBB2 gene amplification occurs in many cancer types and has been identified in $20 \%$ of patients with gastric cancer (2). ERBB2 amplification is an established therapeutic target in breast and gastric cancer $(3,4)$ and can be easily identified by confirming the HER2 overexpression using immunohistochemistry (IHC) (5). In contrast to ERBB2 amplification, the ERBB2 mutation has long been neglected due to its low incidence and lack of available therapeutic options. However, ERBB2 mutation has been recently attracting attention as large-scale sequencing efforts reported recurrent $E R B B 2$ mutations in various solid tumors and $E R B B 2$ mutations were shown to play an oncogenic role like $E R B B 2$ amplification (6-8). Moreover, recent clinical studies of new targeted agents for ERBB2-mutant cancers have shown promising results in solid tumors, particularly breast cancer and non-small cell lung cancer (9-11).

ERBB2 receptors contain an extracellular domain, a transmembrane domain, an intracellular region that consists of a juxtamembrane domain, a kinase domain (exons 18-21), and a C-terminal tail domain (12). ERBB2 mutations occur most frequently in the tyrosine kinase domain region, but mutational hotspots vary among cancer types (7). Importantly, previous clinical trials have revealed that the efficacy of treatment varies according to the location of the ERBB2 mutation $(7,10,13)$. For example, patients receiving neratinib (pan-HER tyrosine kinase inhibitor) with $E R B B 2$ kinase domain point mutations had a response rate of $21.4 \%$, whereas those with exon 20 insertions had a response rate of $7.1 \%$ (10). These variant-specific differences in clinical outcomes demonstrate that a detailed understanding of the 
landscape of ERBB2 mutations is necessary to develop effective therapies.

Given the promising results of target agents for ERBB2mutant tumors in other organs, clinical investigations targeting ERBB2 mutations in gastric cancer are also expected in the near future. However, in gastric cancer, $E R B B 2$ mutations have not been specifically investigated, in contrast to breast and lung cancers (14-16). Herein, we aimed to describe the details of ERBB2 mutations in clinical samples of advanced gastric cancer in a single institute $(\mathrm{n}=234)$ and from a public database $(\mathrm{n}=1,566)$. Unlike $E R B B 2$ amplification, ERBB2 mutations have not been subjected to routine clinical testing; therefore, data on the clinicopathologic findings of ERBB2-mutant cancer are limited (6). We further retrospectively investigated the clinicopathologic features associated with the ERBB2 mutation in gastric cancer, which might help clinicians select the suitable candidates for ERBB2 mutation screening.

\section{Patients and Methods}

Patients. Targeted sequencing was performed in patients with advanced gastric cancer $(n=234)$ as a requirement at the Department of Pathology, Samsung Medical Center (Seoul, Korea) between January 2019 and April 2021. The tissue type was surgical resection in $82(35.0 \%)$ patients and biopsy in $152(65.0 \%)$ patients. Formalin-fixed paraffin-embedded (FFPE) tissue samples were used for targeted sequencing. Patients' clinicopathological information, including age, sex, stage according to the American Joint Committee on Cancer (AJCC) 8th edition (17), pathologic diagnosis, and Lauren classification (18), were evaluated by reviewing the electronic medical records. Data for HER2, programmed death-ligand 1 (PD-L1) and mismatch repair protein expression, as well as for Epstein-Barr virus (EBV), and microsatellite instability (MSI) analysis were also retrieved from the medical records; the protocols (IHC and in situ hybridization; ISH) for these assessments were described in a previous study $(19,20)$. This study was reviewed and approved by the Institutional Review Board of the Samsung Medical Center (2020-06-045-002).

DNA/RNA extraction. Genomic DNA and RNA were extracted from FFPE tissue sections and purified using the QIAGEN AllPrep DNA/RNA FFPE Kit (QIAGEN, Venlo, the Netherlands). Manual microdissection was performed for surgical samples and available biopsy samples. The DNA concentrations were measured using Qubit dsDNA HS Assay Kit (Thermo Fisher Scientific, Waltham, MA, USA). A Genomic DNA ScreenTape (Agilent Technologies, Santa Clara, CA, USA) on an Agilent 2200 TapeStation system (Agilent Technologies) was used to determine the DNA integrity number, measure of the size of the DNA fragments, and DNA quality.

Library preparation, sequencing, and data analysis. Forty nanograms of DNA were quantified using the Qubit dsDNA HS Assay Kit on a Qubit 2.0 Fluorometer (Thermo Fisher Scientific) and then sheared using a Covaris E220 Focused-ultrasonicator (Woburn, MA, USA) and an 8 microTUBE-50 Strip AFA Fiber V2, according to the manufacturer's instructions. For DNA library preparation and enrichment, the TruSight ${ }^{\mathrm{TM}}$ Oncology $500 \mathrm{Kit}$ (Illumina Inc., San Diego, CA, USA) was used according to the manufacturer's instructions. Post-enriched libraries were quantified, pooled, and sequenced using a NextSeq 500 system (Illumina Inc.). The sequencing data were analyzed using the TruSight ${ }^{\mathrm{TM}}$ Oncology 500 Local App version 1.3.0.39 (Illumina), a comprehensive tumor profiling assay designed to identify known tumor biomarkers, including small variants, splice variants, and fusions. The reads were aligned to the reference genome (GRCh37/hg19) using a Burrows-Wheeler Aligner-MEM (21). Poorly mapped reads with a mapping quality below 20 were removed using SAMtools version 1.3.1 (22). Somatic mutations, including single nucleotide variants and small insertions and deletions, were detected by Pisces and Psara (23). The rest of the pipeline were as follows: CRAFT for copy number variation, TmbRaider for tumor mutation burden, Hubble for MSI, STAR for RNA alignment, and Manta for fusion calling (24). Outputs of data exported from the TSO 500 pipeline (24) were annotated using the Ensembl Variant Effect Predictor Annotation Engine, with information from databases, such as the Single Nucleotide Polymorphism (dbSNP), Genome Aggregation (gnomAD; which includes genome and exome data), 1000 Genomes, ClinVar, COSMIC, RefSeq, and Ensembl databases. The processed genomic alterations were categorized into a four-tier system based on the American Society of Clinical Oncology and College of American Pathologists guidelines (25), annotated with proper references. The following criteria were used to filter the insignificant variants and possible germline variants: (i) variants with $<5 \%$ allele frequency and $<100 \times$ read depth at the variant; (ii) variants previously reported to be benign or likely benign in the ClinVar archive (26); and (iii) variants with a frequency greater than $1 \%$ in gnomAD (27) were excluded.

Statistical analysis. Statistical analyses were performed using IBM SPSS for Windows version 27 (IBM Corp., Armonk, NY, USA) and $\mathrm{R}$ software (version 3.6.3; The $\mathrm{R}$ Foundation for Statistical Computing, Vienna, Austria). Pearson's chi-square, Fisher's exact, or Cochran-Armitage trend tests were used to analyze the relationship between $E R B B 2$ mutation status and clinicopathological parameters. A $p$-value of $<0.05$ was considered significant.

\section{Results}

Patient characteristics. All patients were Korean individuals, and the mean age was 58.2 years (range=26-86). On histopathological examination, $177(75.6 \%)$ patients were diagnosed with poorly differentiated carcinoma, while 57 (24.4\%) were diagnosed with well or moderately differentiated carcinoma. Except for 24 patients, who were not available for pathologic staging, majority ( $80.3 \%$ ) of the patients had stage IV disease according to the AJCC $8^{\text {th }}$ staging system at the time of sequencing. There were $21(9.0 \%)$ patients and 1 patient $(0.4 \%)$ who had stages III and II disease, respectively. None of the patients had stage I disease.

ERBB2 mutation in our cohort. Among the 234 gastric cancer patients, ERBB2 mutations were detected in 18 (7.7\%) patients. In one patient, two different types of $E R B B 2$ mutations were detected; a total of 19 ERBB2 mutations 
A

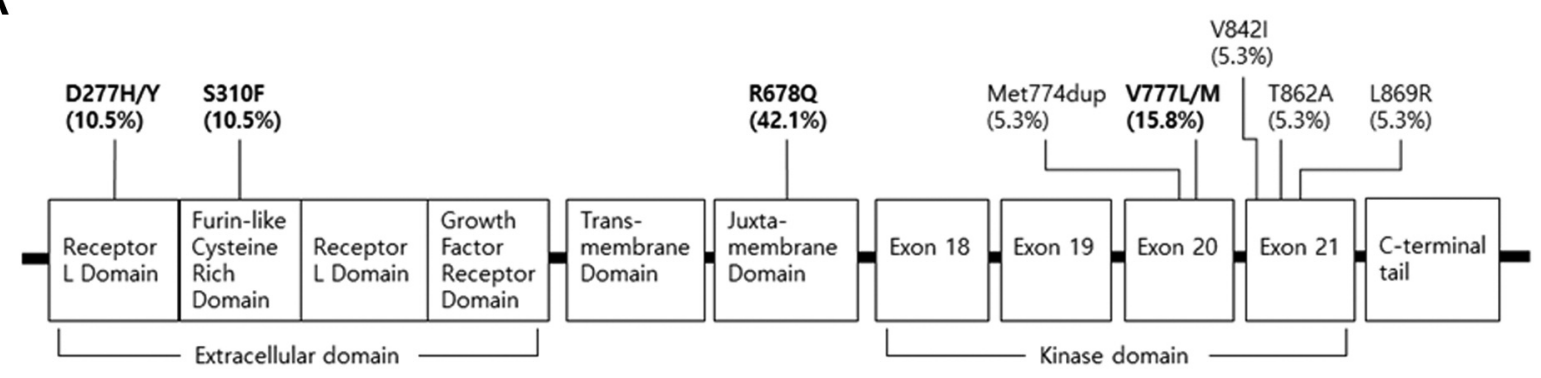

B
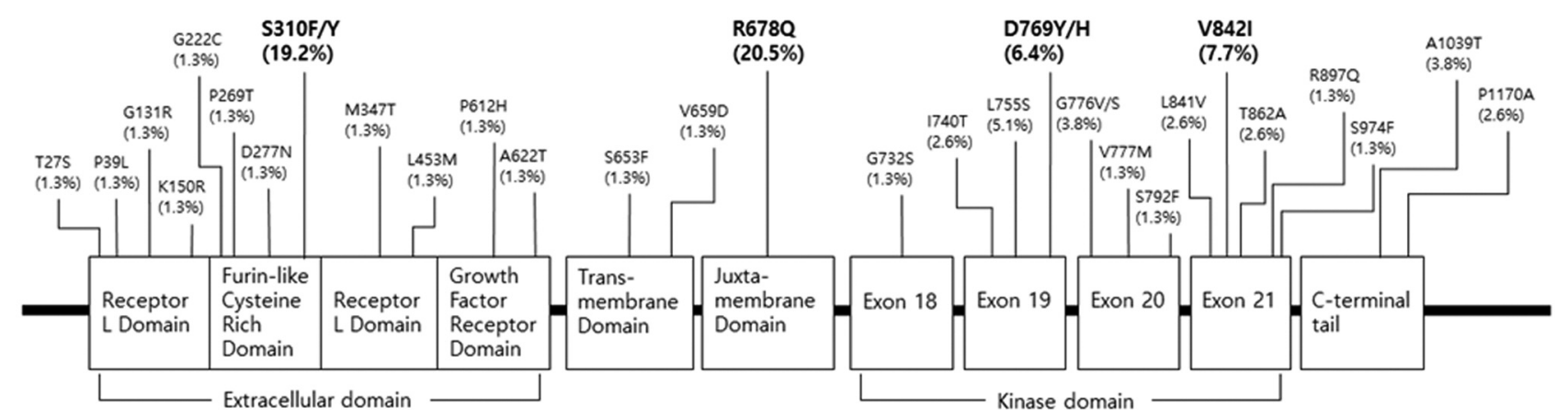

Figure 1. Distribution of ERBB2 mutations in gastric cancer. (A) The locations of ERBB2 mutations in our sequencing cohort ( $n=234)$. (B) The locations of ERBB2 mutations in public databases $(n=1,566)$.

were detected in this population. The distribution of ERBB2 mutations is shown in Figure 1A. The most frequently detected mutation was p.Arg678Gln (R678Q; c.2033G $>$ A) $(\mathrm{n}=8,42.1 \%)$, which is located in the juxtamembrane domain of ERBB2. Seven mutations (36.8\%) were detected in the active region of the tyrosine kinase domain. These mutations were: V777L (c.2329G >T), V777M (c.2329G>A), V842I (c.2524G>A), T862A (c.2584A>G), L869R (c.2606T>G), and p.Met774dup (c.2320_2322dup), all of which were confined to exons 20 and 21 . The remaining $4(21.1 \%)$ mutations occurred in the extracellular domain, and the detected mutations were D277H (c.829G $>$ C), D277Y (c.829G $>$ T), and S310F (c.929C $>$ T). All but one mutation have been previously reported as oncogenic or likely oncogenic according to the public database (ONCOKB; https://www.oncokb.org; May 27, 2021). One ERBB2 duplication mutation, p.Met774dup (c.2320_2322dup), in exon 20 of the kinase domain, has not been reported previously. The variant allele frequency of the detected ERBB2 mutations ranged from $1.6 \%$ to $40 \%$.

ERBB2 mutation in public databases. cBioPortal was utilized to analyze $E R B B 2$ mutations in gastric cancer reported in public databases $(28,29)$. Combining the reports of 9 different studies (MSKCC 2020; TMUCIH, PNAS 2015;
OncoSG, 2018; Pfizer and UHK, Nat Genet 2014; TCGA, Firehose Legacy; TCGA, Nature 2014; TCGA, PanCancer Atlas; U Tokyo, Nat Genet 2014; and UHK Nat Genet 2011) with exclusion of overlapping cases, the frequency of $E R B B 2$ mutation was $4.9 \%$ (78 of 1,566). The frequency of ERBB2 mutation varied among studies, ranging from 3.5 to $3.6 \%$. The distribution of the ERBB2 mutations is shown in Figure 1B. The most common mutation was also R678Q (20.5\%) in the juxtamembrane domain, followed by S310F/Y (19.2\%) in the extracellular domain, and V842I (7.7\%) in the tyrosine kinase domain.

Clinicopathological characteristics of ERBB2-mutant tumors in our cohort. The clinicopathological characteristics of patients with ERBB2 mutation status in our cohort are summarized in Table I. Among the 18 patients with ERBB2 mutation, half were men, and the mean age was 55.3 years (range $=38-82)$. On histologic examination, $15(83.3 \%)$ patients were diagnosed with poorly differentiated carcinoma. According to the Lauren classification (18), 14 (77.8\%) patients had the diffuse type, while $4(22.2 \%)$ had the intestinal type of carcinoma. Except for 2 patients with missing information on pathologic stage, $2(12.5 \%)$ patients had stage III and 14 (87.5\%) had stage IV disease at the time of sequencing. HER2 IHC was performed in all ERBB2- 
Table I. Patient characteristics.

\begin{tabular}{|c|c|c|c|c|}
\hline \multirow[t]{2}{*}{ Variables } & \multicolumn{2}{|c|}{ ERBB2 mutation } & \multirow[t]{2}{*}{ Total } & \multirow[t]{2}{*}{$p$-Value } \\
\hline & ERBB2-mutant & $E R B B 2$-wild & & \\
\hline \multicolumn{5}{|l|}{ Age, years } \\
\hline$<60$ & $13(72.2 \%)$ & $113(52.3 \%)$ & $126(53.8 \%)$ & \multirow[t]{2}{*}{0.104} \\
\hline$\geq 60$ & $5(27.8 \%)$ & $103(47.7 \%)$ & $108(46.2 \%)$ & \\
\hline \multicolumn{5}{|l|}{ Gender } \\
\hline Male & $9(50.0 \%)$ & $82(38.0 \%)$ & $91(38.9 \%)$ & \multirow[t]{2}{*}{0.314} \\
\hline Female & $9(50.0 \%)$ & $134(62.0 \%)$ & $143(61.1 \%)$ & \\
\hline \multicolumn{5}{|l|}{ Histologic type } \\
\hline $\mathrm{W} / \mathrm{D}, \mathrm{M} / \mathrm{D}$ & $3(16.7 \%)$ & $54(25.0 \%)$ & $57(24.4 \%)$ & \multirow[t]{2}{*}{0.429} \\
\hline $\mathrm{P} / \mathrm{D}$ & $15(83.3 \%)$ & $162(75.0 \%)$ & $177(75.6 \%)$ & \\
\hline \multicolumn{5}{|l|}{ Lauren classification } \\
\hline Intestinal & $4(22.2 \%)$ & $63(29.2 \%)$ & $67(28.6 \%)$ & \multirow[t]{4}{*}{$0.398 *$} \\
\hline Diffuse & $14(77.8 \%)$ & $125(57.9 \%)$ & $139(59.4 \%)$ & \\
\hline Mixed & $0(0.0 \%)$ & $23(10.6 \%)$ & $23(9.8 \%)$ & \\
\hline Indeterminate & $0(0.0 \%)$ & $5(2.3 \%)$ & $5(2.1 \%)$ & \\
\hline \multicolumn{5}{|l|}{ Stage } \\
\hline I & $0(0.0 \%)$ & $0(0.0 \%)$ & $0(0.0 \%)$ & \multirow[t]{4}{*}{$0.692 *$} \\
\hline II & $0(0.0 \%)$ & $1(0.5 \%)$ & $1(0.5 \%)$ & \\
\hline III & $2(12.5 \%)$ & $19(9.8 \%)$ & $21(10.0 \%)$ & \\
\hline IV & $14(87.5 \%)$ & $174(89.7 \%)$ & $188(89.5 \%)$ & \\
\hline \multicolumn{5}{|c|}{ HER2 immunohistochemistry } \\
\hline Negative & $18(100.0 \%)$ & $179(89.1 \%)$ & $197(90.0 \%)$ & \multirow[t]{2}{*}{$0.228^{*}$} \\
\hline Positive & $0(0.0 \%)$ & $22(10.9 \%)$ & $22(10.0 \%)$ & \\
\hline \multicolumn{5}{|l|}{ EBV } \\
\hline Negative & $15(93.8 \%)$ & $150(98.0 \%)$ & $165(97.6 \%)$ & \multirow[t]{2}{*}{$0.331 *$} \\
\hline Positive & $1(6.3 \%)$ & $3(2.0 \%)$ & $4(2.4 \%)$ & \\
\hline \multicolumn{5}{|l|}{ MSI } \\
\hline MSS & $17(94.4 \%)$ & $212(98.1 \%)$ & $229(97.9 \%)$ & \multirow[t]{2}{*}{$0.332 *$} \\
\hline MSI-high & $1(5.6 \%)$ & $4(1.9 \%)$ & $5(2.1 \%)$ & \\
\hline \multicolumn{5}{|c|}{ Tumor mutation burden } \\
\hline Low & $17(94.4 \%)$ & $192(88.9 \%)$ & $209(89.3 \%)$ & \multirow[t]{2}{*}{$0.702 *$} \\
\hline High & $1(5.6 \%)$ & $24(11.1 \%)$ & $25(10.7 \%)$ & \\
\hline \multicolumn{5}{|l|}{ PD-L1 } \\
\hline Negative $(\mathrm{CPS}=0)$ & $3(23.1 \%)$ & $38(29.2 \%)$ & $41(28.7 \%)$ & \multirow[t]{2}{*}{$0.758 *$} \\
\hline Positive (CPS $\geq 1$ ) & $10(76.9 \%)$ & $92(70.8 \%)$ & $102(71.3 \%)$ & \\
\hline
\end{tabular}

W/D, Well differentiated; M/D, moderately differentiated; P/D, poorly differentiated; EBV, Epstein-barr virus; MSI, microsatellite instability; MSS, microsatellite stable; PD-L1, programmed cell death ligand-1; CPS, combined positive score. *by Fisher's exact test.

mutant tumors, and all were HER2 negative. EBV ISH was performed in 16 patients, and only one $(6.3 \%)$ patient was EBV positive. PD-L1 IHC was performed in 13 out of 18 patients, and 10 (76.9\%) patients were positive with combined positive scores of 1 to 70 .

Next, we compared ERBB2-mutant tumors and ERBB2 wild-type tumors to identify the clinicopathological features associated with ERBB2 mutation in gastric cancer (Table I). However, there was no factor significantly associated with $E R B B 2$ mutation, possibly due to the small number of ERBB2-mutant cases.

Co-occurring alterations of ERBB2-mutant tumors in our cohort. Table II summarizes the coexisting genetic alterations (pathogenic/likely pathogenic only) detected by targeted sequencing of 18 ERBB2-mutant tumors. Coexisting single nucleotide variants were detected in $10(55.6 \%)$ patients. Copy number alteration was detected in one (5.6\%) patient, and no fusion was detected. No additional significant alterations were detected other than the ERBB2 mutation in 7 (38.8\%) patients. The most common single nucleotide variants were ATM mutation $(\mathrm{n}=3,16.7 \%)$, KRAS mutation $(\mathrm{n}=3,16.7 \%)$, and PIK3CA mutation $(\mathrm{n}=2,11.1 \%)$. Three ATM mutations were previously reported as pathogenic germline variants (NM_000051.3 [ATM]:c.103C >T [p.Arg35Ter], c.8977C >T [p.Arg2993Ter], and c.8432del [p.Lys2811fs]). Considering the high variant allele frequency in patients 8 and 10 , the possibility of a germline variant is present. BRCA2, SF3B1, 
Table II. Co-occurring alterations detected in ERBB2 mutated cases.

\begin{tabular}{|c|c|c|c|c|c|c|c|}
\hline \multirow[t]{2}{*}{ Patient no. } & \multirow{2}{*}{$\begin{array}{c}E R B B 2 \\
\text { mutation }\end{array}$} & \multicolumn{4}{|c|}{ Co-occurring single nucleotide variant } & \multicolumn{2}{|c|}{ Copy number alteration } \\
\hline & & Gene & c.DNA & Amino acid & VAF & Gene & Copy number \\
\hline 2 & p.Met774dup & PIK3CA & c. $1624 \mathrm{G}>\mathrm{A}$ & p.Glu542Lys & $4.30 \%$ & & \\
\hline 3 & p.Arg678Gln & $P I K 3 C A$ & c. $1624 \mathrm{G}>\mathrm{A}$ & p.Glu542Lys & $13.40 \%$ & & \\
\hline 8 & p.Val842Ile & $A T M$ & c. $103 \mathrm{C}>\mathrm{T}$ & p.Arg35Ter & $39.00 \%$ & & \\
\hline 9 & & & & & & $F G F R 2$ & 32.8 \\
\hline 10 & p.Arg678Gln & ATM & c. $8977 \mathrm{C}>\mathrm{T}$ & p.Arg2993Ter & $45.90 \%$ & & \\
\hline \multirow[t]{2}{*}{11} & p.Arg678Gln & $B R C A 2$ & c.7667del & p.Asn2556MetfsTer92 & $4.20 \%$ & & \\
\hline & & $S F 3 B 1$ & c. $2098 \mathrm{~A}>\mathrm{G}$ & p.Lys700Glu & $4.00 \%$ & & \\
\hline 12 & p.Thr862Ala & KRAS & c. $38 \mathrm{G}>\mathrm{A}$ & p.Gly13Asp & $1.50 \%$ & & \\
\hline \multirow[t]{4}{*}{13} & p.Val777Met & KRAS & c. $35 \mathrm{G}>\mathrm{A}$ & p.Gly12Asp & $4.30 \%$ & & \\
\hline & & $A T M$ & c.8432del & p.Lys2811SerfsTer46 & $13.80 \%$ & & \\
\hline & & PTEN & c.801del & p.Lys267ArgfsTer9 & $4.10 \%$ & & \\
\hline & & PTEN & c. $389 \mathrm{C}>\mathrm{T}$ & p.Arg130Ter & $3.40 \%$ & & \\
\hline 14 & p.Arg678Gln & $M A P 2 K 1$ & c. $167 \mathrm{~A}>\mathrm{C}$ & p.Gln56Pro & $9.10 \%$ & & \\
\hline 15 & p.Asp277Tyr & KRAS & c. $35 \mathrm{G}>\mathrm{A}$ & p.Gly 12 Asp & $20.60 \%$ & & \\
\hline 16 & p.Arg678Gln & $K D M 6 A$ & c. $2125 \mathrm{C}>\mathrm{T}$ & p.Gln709Ter & $30.00 \%$ & & \\
\hline
\end{tabular}

VAF, Variant allele frequency.

$M A P 2 K 1$, and $K D M 6 A$ mutations were detected in one patient. A coexisting FGFR2 amplification (estimated copy number: 32.8) was detected in patient 9. No co-occurring ERBB2 amplification was identified in other patients.

The tumor mutation burden was categorized as high in only one $(5.6 \%)$ patient, and this patient showed a MSI-high status. The detected ERBB2 variant was V777M (c.2329G>A).

\section{Discussion}

The evidence supporting HER2-directed drugs in ERBB2mutant cancers is promising and is rapidly growing in various solid tumors. Whereas ERBB2 amplification is a well-established target in the treatment of advanced gastric cancers, ERBB2 mutations have not been specifically investigated in gastric cancer. Several preclinical and clinical studies have shown that ERBB2 mutation hotspots vary across cancer types, which is closely associated with drug sensitivity $(6,7,10)$. In the present study, we investigated the frequency, mutation details, and clinicopathological features of $E R B B 2$ mutations in gastric cancer.

The frequency of ERBB2 mutation was $7.7 \%$ (18 of 234 patients), which is slightly higher than the reported frequency in gastric cancer $(\sim 4.5 \%)$ (7). The most common ERBB2 mutation was R678Q in the juxtamembrane domain, followed by mutations in the tyrosine kinase and extracellular domains. R678Q was also the most common mutation in gastric cancer as per public databases. This contrasts with other tumor types where the majority of ERBB2 mutations are located within the kinase and extracellular domains (7). Unlike other oncogenes, such as $B R A F$ or $K R A S, E R B B 2$ has no single predominant mutant allele, and the distribution of mutations varies by tumor type (10). Across all cancer types, the most common location is the tyrosine kinase domain, and the most common single mutation is $\mathrm{S} 310 \mathrm{~F} / \mathrm{Y}$, which is detected in the extracellular domain (7). Among other tumors with positive response to antiHER2 therapy, the most common ERBB2 mutation in non-small cell lung cancer and breast cancer was located in the tyrosine kinase domains of exons 20 and 19, respectively (7). The treatment effect of anti-HER2 agents has been mostly reported in tumors with $E R B B 2$ tyrosine kinase domain mutations (10).

The juxtamembrane domain is a relatively short region in the intracellular domain, containing 39 amino acids, whose function is receptor dimerization and stability (12). Juxtamembrane domain mutations are relatively rare, accounting for up to $7.7 \%$ of the mutations in reported cases of all cancer types (12). R678Q was most common in transmembrane/juxtamembrane domain mutations and accounted for 3.5\%-5.0\% of all ERBB2 mutations (12). To the best of our knowledge, no clinical study has investigated the use of an anti-HER2 therapy for ERBB2 R678Q-mutant tumors. However, preclinical studies have revealed that R678Q enhances HER2 activity by stabilizing an activating conformation and confers sensitivity to anti-HER2 therapy (12). In vitro studies of breast cancer showed that the R678Q mutation is an activating mutation that is sensitive to targeted treatment with trastuzumab, lapatinib, afatinib, and neratinib $(10,12)$. Other than R678Q, the mutations were dispersed throughout the tyrosine kinase domain and extracellular domains, nearly all of which were previously detected in public databases (http://www.cbioportal.org; May 27, 2021). One duplication mutation in exon 20, p.Met774dup (c.2320_2322dup), has not been previously reported. This 
mutation was detected close to the common exon 20 insertion, Y772dupYVMA (7).

Next, we evaluated the clinicopathological features of $E R B B 2$-mutant gastric cancer in our cohort. Consistent with the findings of previous studies $(6,30)$, all $E R B B 2$ mutated cases were negative for HER2 IHC. ERBB2 amplification and mutation are mostly mutually exclusive, and ERBB2-mutant tumors do not overexpress HER2 protein like ERBB2amplified tumors (6). In other tumors, ERBB2 mutations are reported to be enriched in certain histological types, such as high-grade lobular breast carcinomas (31). In the present study, we failed to identify the clinicopathological features associated with $E R B B 2$ mutation in gastric cancer, possibly due to the small number of cases. However, it appears that ERBB2-mutant gastric cancers are mainly detected in tumors with poor differentiation, negative HER2 IHC results, negative EBV ISH results, and microsatellite stable status, considering the known proportion of those biomarkers in gastric cancer.

The impact of $E R B B 2$ mutations is likely to be affected by coexisting mutations (6). Previously, ERBB2 mutations were reported to display significant co-occurrence with $E R B B 3$, $R A F 1, P I K 3 C A$, and $P I K 3 R 2$ alterations but mutually exclusive with $K R A S$ alterations in other solid tumors (30). However, in our study, coexisting KRAS mutations were detected in three patients. Notably, pathogenic $A T M$ variants were detected in these three ERBB2-mutant patients. Future preclinical and clinical studies investigating the role of coexisting mutations in ERBB2-mutant gastric cancer are warranted.

The present study has the following limitations: the number of patients was relatively small and only the Asian population was assessed. Hence, further studies in a large number of gastric cancer patients are warranted to examine the association between $E R B B 2$ mutations and clinicopathological factors.

In conclusion, comprehensive panel sequencing detected $E R B B 2$ mutations in patients with gastric cancer. The most commonly detected variant was R678Q in the juxtamembrane domain in our cohort and public databases. All ERBB2-mutated tumors were negative for HER2 expression, which confirmed that it is not possible to detect ERBB2 mutation by HER2 IHC. Our study might provide useful information for the development of anti-HER2 therapy for ERBB2-mutant gastric cancers.

\section{Conflicts of Interest}

No potential conflicts of interest exist.

\section{Authors' Contributions}

S. A. and K-M. K. designed and supervised the study. S. P. evaluated the data, performed the clinicopathologic analysis, and wrote the manuscript. D. G. K., S. K., and H. K. assisted with the data analysis and writing of the manuscript. All authors have read and approved the final manuscript.

\section{Acknowledgements}

This work was supported by the Basic Science Research Program through the National Research Foundation of Korea funded by the Ministry of Science and ICT (NRF-2017R1E1A1A01075005) and a grant from the Korea Health Technology R\&D Project through the Korea Health Industry Development Institute, funded by the Ministry of Health \& Welfare, Republic of Korea (grant numbers: HR20C0025 and HI21C1137).

\section{References}

1 Akiyama T, Sudo C, Ogawara H, Toyoshima K and Yamamoto T: The product of the human c-erbB-2 gene: a 185-kilodalton glycoprotein with tyrosine kinase activity. Science 232(4758): 16441646, 1986. PMID: 3012781. DOI: 10.1126/science.3012781

2 Abrahao-Machado LF and Scapulatempo-Neto C: HER2 testing in gastric cancer: An update. World J Gastroenterol 22(19): 46194625, 2016. PMID: 27217694. DOI: 10.3748/wjg.v22.i19.4619

3 Bang YJ, Van Cutsem E, Feyereislova A, Chung HC, Shen L, Sawaki A, Lordick F, Ohtsu A, Omuro Y, Satoh T, Aprile G, Kulikov E, Hill J, Lehle M, Rüschoff J, Kang YK and ToGA Trial Investigators: Trastuzumab in combination with chemotherapy versus chemotherapy alone for treatment of HER2-positive advanced gastric or gastro-oesophageal junction cancer (ToGA): a phase 3, open-label, randomised controlled trial. Lancet 376(9742): 687-697, 2010. PMID: 20728210. DOI: 10.1016/S0140-6736(10)61121-X

4 Gravalos C and Jimeno A: HER2 in gastric cancer: a new prognostic factor and a novel therapeutic target. Ann Oncol 19(9): 1523-1529, 2008. PMID: 18441328. DOI: 10.1093/annonc/mdn 169

5 Bartley AN, Washington MK, Ventura CB, Ismaila N, Colasacco C, Benson AB 3rd, Carrato A, Gulley ML, Jain D, Kakar S, Mackay HJ, Streutker C, Tang L, Troxell M and Ajani JA: HER2 Testing and Clinical Decision Making in Gastroesophageal Adenocarcinoma: Guideline from the College of American Pathologists, American Society for Clinical Pathology, and American Society of Clinical Oncology. Arch Pathol Lab Med 140(12): 1345-1363, 2016. PMID: 27841667. DOI: 10.5858/ arpa.2016-0331-CP

6 Connell CM and Doherty GJ: Activating HER2 mutations as emerging targets in multiple solid cancers. ESMO Open 2(5): e000279, 2017. PMID: 29209536. DOI: 10.1136/esmoopen2017-000279

7 Robichaux JP, Elamin YY, Vijayan RSK, Nilsson MB, Hu L, He J, Zhang F, Pisegna M, Poteete A, Sun H, Li S, Chen T, Han H, Negrao MV, Ahnert JR, Diao L, Wang J, Le X, Meric-Bernstam F, Routbort M, Roeck B, Yang Z, Raymond VM, Lanman RB, Frampton GM, Miller VA, Schrock AB, Albacker LA, Wong KK, Cross JB and Heymach JV: Pan-cancer landscape and analysis of ERBB2 mutations identifies poziotinib as a clinically active inhibitor and enhancer of T-DM1 activity. Cancer Cell 36(4): 444457.e7, 2019. PMID: 31588020. DOI: 10.1016/j.ccell.2019.09.001

8 Conlon NT, Kooijman JJ, van Gerwen SJC, Mulder WR, Zaman GJR, Diala I, Eli LD, Lalani AS, Crown J and Collins DM: Comparative analysis of drug response and gene profiling of HER2targeted tyrosine kinase inhibitors. Br J Cancer 124(7): 1249-1259, 2021. PMID: 33473169. DOI: 10.1038/s41416-020-01257-x

9 Li BT, Shen R, Buonocore D, Olah ZT, Ni A, Ginsberg MS, Ulaner GA, Offin M, Feldman D, Hembrough T, Cecchi F, 
Schwartz S, Pavlakis N, Clarke S, Won HH, Brzostowski EB, Riely GJ, Solit DB, Hyman DM, Drilon A, Rudin CM, Berger MF, Baselga J, Scaltriti M, Arcila ME and Kris MG: Ado-trastuzumab emtansine for patients with HER2-mutant lung cancers: Results from a phase II basket trial. J Clin Oncol 36(24): 2532-2537, 2018. PMID: 29989854. DOI: 10.1200/JCO.2018.77.9777

10 Hyman DM, Piha-Paul SA, Won H, Rodon J, Saura C, Shapiro GI, Juric D, Quinn DI, Moreno V, Doger B, Mayer IA, Boni V, Calvo E, Loi S, Lockhart AC, Erinjeri JP, Scaltriti M, Ulaner GA, Patel J, Tang J, Beer H, Selcuklu SD, Hanrahan AJ, Bouvier N, Melcer M, Murali R, Schram AM, Smyth LM, Jhaveri K, Li BT, Drilon A, Harding JJ, Iyer G, Taylor BS, Berger MF, Cutler RE Jr, Xu F, Butturini A, Eli LD, Mann G, Farrell C, Lalani AS, Bryce RP, Arteaga CL, Meric-Bernstam F, Baselga J and Solit DB: HER kinase inhibition in patients with HER2- and HER3mutant cancers. Nature 554(7691): 189-194, 2018. PMID: 29420467. DOI: $10.1038 /$ nature 25475

11 Ma CX, Bose R, Gao F, Freedman RA, Telli ML, Kimmick G, Winer E, Naughton M, Goetz MP, Russell C, Tripathy D, Cobleigh M, Forero A, Pluard TJ, Anders C, Niravath PA, Thomas S, Anderson J, Bumb C, Banks KC, Lanman RB, Bryce R, Lalani AS, Pfeifer J, Hayes DF, Pegram M, Blackwell K, Bedard PL, Al-Kateb H and Ellis MJC: Neratinib efficacy and circulating tumor DNA detection of HER2 mutations in HER2 nonamplified metastatic breast cancer. Clin Cancer Res 23(19): 5687-5695, 2017. PMID: 28679771. DOI: 10.1158/10780432.CCR-17-0900

12 Pahuja KB, Nguyen TT, Jaiswal BS, Prabhash K, Thaker TM, Senger K, Chaudhuri S, Kljavin NM, Antony A, Phalke S, Kumar P, Mravic M, Stawiski EW, Vargas D, Durinck S, Gupta R, Khanna-Gupta A, Trabucco SE, Sokol ES, Hartmaier RJ, Singh A, Chougule A, Trivedi V, Dutt A, Patil V, Joshi A, Noronha V, Ziai J, Banavali SD, Ramprasad V, DeGrado WF, Bueno R, Jura $\mathrm{N}$ and Seshagiri S: Actionable activating oncogenic ERBB2/HER2 transmembrane and juxtamembrane domain mutations. Cancer Cell 34(5): 792-806.e5, 2018. PMID: 30449325. DOI: 10.1016/j.ccell.2018.09.010

13 Robichaux JP, Elamin YY, Tan Z, Carter BW, Zhang S, Liu S, Li S, Chen T, Poteete A, Estrada-Bernal A, Le AT, Truini A, Nilsson MB, Sun H, Roarty E, Goldberg SB, Brahmer JR, Altan M, Lu C, Papadimitrakopoulou V, Politi K, Doebele RC, Wong KK and Heymach JV: Mechanisms and clinical activity of an EGFR and HER2 exon 20-selective kinase inhibitor in non-small cell lung cancer. Nat Med 24(5): 638-646, 2018. PMID: 29686424. DOI: 10.1038/s41591-018-0007-9

14 Wei XW, Gao X, Zhang XC, Yang JJ, Chen ZH, Wu YL and Zhou Q: Mutational landscape and characteristics of ERBB2 in non-small cell lung cancer. Thorac Cancer 11(6): 1512-1521, 2020. PMID: 32291971. DOI: 10.1111/1759-7714.13419

15 Ross JS, Gay LM, Wang K, Ali SM, Chumsri S, Elvin JA, Bose R, Vergilio JA, Suh J, Yelensky R, Lipson D, Chmielecki J, Waintraub S, Leyland-Jones B, Miller VA and Stephens PJ: Nonamplification ERBB2 genomic alterations in 5605 cases of recurrent and metastatic breast cancer: An emerging opportunity for anti-HER2 targeted therapies. Cancer 122(17): 2654-2662, 2016. PMID: 27284958. DOI: 10.1002/cncr.30102

16 Mazières $\mathrm{J}$, Peters $\mathrm{S}$, Lepage $\mathrm{B}$, Cortot $\mathrm{AB}$, Barlesi F, BeauFaller M, Besse B, Blons H, Mansuet-Lupo A, Urban T, MoroSibilot D, Dansin E, Chouaid C, Wislez M, Diebold J, Felip E, Rouquette I, Milia JD and Gautschi O: Lung cancer that harbors an HER2 mutation: epidemiologic characteristics and therapeutic perspectives. J Clin Oncol 31(16): 1997-2003, 2013. PMID: 23610105. DOI: $10.1200 / J C O .2012 .45 .6095$

17 Amin MB ES, Greene F, Byrd DR, Brookland RK, Washington MK, Gershenwald JE, Compton CC, Hess KR, Sullivan DC, Jessup JM, Brierley JD, Gaspar LE, Schilsky RL, Balch CM, Winchester DP, Asare EA, Madera M, Gress DM and Meyer LR (eds.): AJCC Cancer Staging Manual. 8th ed. New York, Springer, 2017.

18 Lauren P: The two histological main types of gastric carcinoma: Diffuse and so-called intestinal-type carcinoma. An attempt at a histo-clinical classification. Acta Pathol Microbiol Scand 64: 31 49, 1965. PMID: 14320675. DOI: 10.1111/apm.1965.64.1.31

19 Cho J, Ahn S, Son DS, Kim NK, Lee KW, Kim S, Lee J, Park SH, Park JO, Kang WK, An JY, Choi MG, Lee JH, Sohn TS, Bae JM, Kim S and Kim KM: Bridging genomics and phenomics of gastric carcinoma. Int J Cancer 145(9): 2407-2417, 2019. PMID: 30801717. DOI: 10.1002/ijc.32228

20 Ahn S and Kim KM: PD-L1 expression in gastric cancer: interchangeability of $22 \mathrm{C} 3$ and $28-8$ pharmDx assays for responses to immunotherapy. Mod Pathol 34(9): 1719-1727, 2021. PMID: 34002009. DOI: 10.1038/s41379-021-00823-9

$21 \mathrm{Li} \mathrm{H}$ : Aligning sequence reads, clone sequences and assembly contigs with BWA-MEM. arXiv 1303.3997v2, 2013.

22 Li H, Handsaker B, Wysoker A, Fennell T, Ruan J, Homer N, Marth G, Abecasis G, Durbin R and 1000 Genome Project Data Processing Subgroup: The sequence alignment/map format and SAMtools. Bioinformatics 25(16): 2078-2079, 2009. PMID: 19505943. DOI: 10.1093/bioinformatics/btp352

23 Dunn T, Berry G, Emig-Agius D, Jiang Y, Lei S, Iyer A, Udar N, Chuang HY, Hegarty J, Dickover M, Klotzle B, Robbins J, Bibikova M, Peeters M and Strömberg M: Pisces: an accurate and versatile variant caller for somatic and germline nextgeneration sequencing data. Bioinformatics 35(9): 1579-1581, 2019. PMID: 30304370. DOI: 10.1093/bioinformatics/bty 849

24 Pestinger V, Smith M, Sillo T, Findlay JM, Laes JF, Martin G, Middleton G, Taniere P and Beggs AD: Use of an integrated pan-cancer oncology enrichment next-generation sequencing assay to measure tumour mutational burden and detect clinically actionable variants. Mol Diagn Ther 24(3): 339-349, 2020. PMID: 32306292. DOI: 10.1007/s40291-020-00462-x

25 Li MM, Datto M, Duncavage EJ, Kulkarni S, Lindeman NI, Roy S, Tsimberidou AM, Vnencak-Jones CL, Wolff DJ, Younes A and Nikiforova MN: Standards and guidelines for the interpretation and reporting of sequence variants in cancer: A joint consensus recommendation of the Association for Molecular Pathology, American Society of Clinical Oncology, and College of American Pathologists. J Mol Diagn 19(1): 4-23, 2017. PMID: 27993330. DOI: 10.1016/j.jmoldx.2016.10.002

26 Landrum MJ, Lee JM, Benson M, Brown G, Chao C, Chitipiralla S, Gu B, Hart J, Hoffman D, Hoover J, Jang W, Katz K, Ovetsky M, Riley G, Sethi A, Tully R, Villamarin-Salomon R, Rubinstein W and Maglott DR: ClinVar: public archive of interpretations of clinically relevant variants. Nucleic Acids Res 44(D1): D862-D868, 2016. PMID: 26582918. DOI: 10.1093/nar/ gkv1222

27 Karczewski KJ, Francioli LC, Tiao G, Cummings BB, Alföldi J, Wang Q, Collins RL, Laricchia KM, Ganna A, Birnbaum DP, Gauthier LD, Brand H, Solomonson M, Watts NA, Rhodes D, Singer-Berk M, England EM, Seaby EG, Kosmicki JA, Walters 
RK, Tashman K, Farjoun Y, Banks E, Poterba T, Wang A, Seed C, Whiffin N, Chong JX, Samocha KE, Pierce-Hoffman E, Zappala Z, O'Donnell-Luria AH, Minikel EV, Weisburd B, Lek M, Ware JS, Vittal C, Armean IM, Bergelson L, Cibulskis K, Connolly KM, Covarrubias M, Donnelly S, Ferriera S, Gabriel S, Gentry J, Gupta N, Jeandet T, Kaplan D, Llanwarne C, Munshi R, Novod S, Petrillo N, Roazen D, Ruano-Rubio V, Saltzman A, Schleicher M, Soto J, Tibbetts K, Tolonen C, Wade G, Talkowski ME, Genome Aggregation Database Consortium, Neale BM, Daly MJ and MacArthur DG: The mutational constraint spectrum quantified from variation in 141,456 humans. Nature 581(7809): 434-443, 2020. PMID: 32461654. DOI: $10.1038 / \mathrm{s} 41586-020-2308-7$

28 Cerami E, Gao J, Dogrusoz U, Gross BE, Sumer SO, Aksoy BA, Jacobsen A, Byrne CJ, Heuer ML, Larsson E, Antipin Y, Reva B, Goldberg AP, Sander C and Schultz N: The cBio cancer genomics portal: an open platform for exploring multidimensional cancer genomics data. Cancer Discov 2(5): 401-404, 2012. PMID: 22588877. DOI: $10.1158 / 2159-8290 . C D-12-0095$

29 Gao J, Aksoy BA, Dogrusoz U, Dresdner G, Gross B, Sumer SO, Sun Y, Jacobsen A, Sinha R, Larsson E, Cerami E, Sander C and Schultz N: Integrative analysis of complex cancer genomics and clinical profiles using the cBioPortal. Sci Signal 6(269): pl1, 2013. PMID: 23550210. DOI: 10.1126/scisignal.2004088
30 Subramanian J, Katta A, Masood A, Vudem DR and Kancha RK: Emergence of ERBB2 mutation as a biomarker and an actionable target in solid cancers. Oncologist 24(12): e1303-e1314, 2019. PMID: 31292270. DOI: 10.1634/theoncologist.2018-0845

31 Deniziaut G, Tille JC, Bidard FC, Vacher S, Schnitzler A, Chemlali W, Trémoulet L, Fuhrmann L, Cottu P, Rouzier R, Bièche I and Vincent-Salomon A: ERBB2 mutations associated with solid variant of high-grade invasive lobular breast carcinomas. Oncotarget 7(45): 73337-73346, 2016. PMID: 27602491. DOI: $10.18632 /$ oncotarget.11819
Received August 2, 2021 Revised September 19, 2021 Accepted October 20, 2021 